\title{
Special Issue on Desistance Across the Life-Course, Volume 2: Editorial Introduction
}

\author{
Paul Mazerolle ${ }^{1} \cdot$ Tara Renae McGee $^{1}$ \\ Published online: 8 April 2019 \\ (C) Springer Nature Switzerland AG 2019
}

As we stated in the previous special issue on desistance across the life-course, research on this topic has come of age. The sheer volume of responses to our call for papers on this topic is testament to this, and we are pleased to present our readers with the second special issue of the Journal of Developmental and Life-Course Criminology on this topic. As the previous special issue demonstrated, current research on desistance demonstrates theoretical richness, methodological sophistication and analytical breadth.

The current collection of manuscripts further illustrates the importance of this area of scholarship for advancing knowledge and understanding of desistance across the lifecourse and the associated implications for theory, method and practise. Indeed, the included manuscripts illustrate the implications for understanding desistance when considering the time window under examination. Furthermore, the papers illustrate the importance of empirically testing leading theoretical understandings of desistance as well as in examining the associations and mechanisms linking the leading precursors of desistance.

We could not be more thrilled by the response to this call for papers on desistance. It is anticipated that this growing collection of manuscripts will continue to spurn further theoretical and empirical interest on this topic over time. Indeed, by advancing the boundaries of extant theories and research on desistance, the current collections illuminate areas of confirmation and disconfirmation in respect of current knowledge and understanding of desistance across the life-course. Indeed, the seeds for asking new questions and advancing new insights may well spring from the expanding range of manuscripts on desistance that have been presented in the Journal of Developmental and Life-Course Criminology. It is without doubt a fruitful time for research and theory

Paul Mazerolle

p.mazerolle@griffith.edu.au

Tara Renae McGee

tr.mcgee@griffith.edu.au

1 Griffith Criminology Institute, Griffith University, Brisbane, Australia 
on this important component of offending across the life-course and we are especially thankful to the many authors who are pursuing this area of scholarship.

\section{Overview}

In the first paper in this special issue, David Farrington presents new data from the Cambridge Study in Delinquent Development. His paper, entitled, The Duration of Criminal Careers: How Many Offenders Do Not Desist up to Age 61?, explores new ground given that the men in this study have now been followed up in official records to 61 years of age. Farrington explores the prevalence of desistance from offending and found that individuals who had been conviction-free for 30 years had probably desisted from crime. However, this was less likely for those with shorted conviction-free periods.

A key issue in studying desistance involves the length of the follow-up period to observe patterns and processes of desistance. In the second entry of this special issue, Mariel Alper explores this issue in her paper, Is desistance invariant across time and geography? Examining desistance in released prisoners from 30 states over 9 years. In this paper, the author has mapped the criminal histories of a large sample of 70,000 prisoners from their first offence to 9 years after their release from prison in 2005 , across 30 states in the USA. By embracing such a comprehensive and wholistic view, the author has exposed the limitations of studying desistance with short follow-up periods and limited jurisdiction data. The findings reveal that using shorter time periods and within-jurisdiction data identified different people as desisters compared to data from longer follow-ups and multiple jurisdictions.

Empirical tests of theoretical presentations of desistance is a burgeoning area of interest. The third and fourth papers in this special edition illustrate the vibrancy of this area. The paper by Beverley Crank and Timothy Brezina, Self-Control, the Life Course, and Desistance from Crime: A Partial Test of Pratt's Integrated Self-Control/LifeCourse Theory of Offending, empirically explores an 'integrated theory' that advances the idea that self-control theory and life-course perspectives are complementary in nature, particularly by considering self-control as a dynamic rather than static risk factor. Their research examined within-person changes in self-control and shows that increases in self-control exert both direct and indirect effects on offending.

The fourth paper, also an empirical test of theory by Tricia Johnson and Timothy Brezina, is equally as significant. Their paper, Agency, Self-Efficacy, and Desistance from Crime: An Application of Social Cognitive Theory, uses within-person analyses to examine offenders' own confidence in their capacity to desist from offending. The results show that the participants' self-efficacy was enhanced by perceived opportunities relating to school and work, self-control, and resistance to peer influence. These mechanisms were in turn associated with a decrease in criminal involvement.

The experience of victimization may provide a unique context for understanding desistance. The fifth paper in this special issue, Victimization and Desistance from Crime by Jillian Turanovic, examines desistance mechanisms for a sub-sample of 190 victimized male offenders drawn from the Pathways to Desistance Study. Her findings reveal that their desistance from offending could be explained by reducing affiliations with deviant peers. Moreover, an interesting context for enhancing engagement with more prosocial peers involved reducing their binge drinking and becoming a father. 
Self-identity continues to be an important context for understanding desistance. The final paper in this special issue entitled, Identity, Peer Resistance, and Antisocial Influence: Modeling Proximal and Distal Causes of Desistance from Delinquency, also employs data from the Pathways to Desistance Study. In this paper, authors Megan Forney and Jeffrey Ward aim to disentangle the causal ordering of positive self-identity, resistance to antisocial peers, and delinquency. They found significant within-wave associations among all the variables, but over time, the relationships were not observed. Interestingly, they identified an indirect pathway from resistance to peer influence to delinquency through the influence of self-identity.

This collection of manuscripts complements the previous special edition in 2018 and illustrates the strong intellectual interest in desistance research and theory. Undoubtedly, the Journal of Developmental and Life-Course Criminology will continue to receive important manuscripts on this topic in the years ahead. Suffice to say, we have been heartened by the response to the call for papers on this topic, as well as the quality and variety of the manuscripts that have been received and published. This not only illustrates the vibrant nature of this topic of interest for criminology and related disciplines, but also demonstrates and foreshadows the emerging new insights toward fostering a greater awareness and understanding of desistance from crime across the life-course and the associated implications for theory, method, and practise. Long may it continue!

Publisher's Note Springer Nature remains neutral with regard to jurisdictional claims in published maps and institutional affiliations. 